\title{
Bcr-Abl (b3a2)-Derived Peptide Vaccine
}

National Cancer Institute

\section{Source}

National Cancer Institute. Bcr-Abl(b3a2)-Derived Peptide Vaccine. NCI Thesaurus. Code C61310.

A peptide vaccine consisting of the bcr-abl b3a2 fusion oncoprotein, frequently expressed in chronic myelogenous leukemia (CML), with potential antineoplastic activity. Vaccination with the bcr-abl (b3a2)-derived peptide vaccine may stimulate the host immune system to mount a cytotoxic $\mathrm{T}$ lymphocyte $(\mathrm{CT} \mathrm{L})$ response against tumor cells that express the bcr-abl b3a2 fusion protein. Fusion genes in CML typically result from the fusion of either BCR exon b2 or BCR exon b3 to ABL exon a2, a 'b3a2' or a 'b2a2' fusion. 